\title{
The Impact of Organizational Culture on Employee's Satisfaction at the Jordanian Company of Investments "Safeway"
}

\author{
Bassam Mohammad Abu Khadar \\ Al-Huson University, College, Al-Balqa’ Applied University, Al-Huson, Jordan \\ Email:khdairbassam@yahoo.com
}

How to cite this paper: Khadar, B.M.A. (2018) The Impact of Organizational Culture on Employee's Satisfaction at the Jordanian Company of Investments "Safeway". American Journal of Industrial and Business Management, 8, 13-26.

https://doi.org/10.4236/ajibm.2018.81002

Received: December 4, 2017

Accepted: January 7, 2018

Published: January 10, 2018

Copyright $\odot 2018$ by author and Scientific Research Publishing Inc. This work is licensed under the Creative Commons Attribution International License (CC BY 4.0).

http://creativecommons.org/licenses/by/4.0/

\begin{abstract}
This paper mainly studies a "Safeway store" as a field study. Generally, job satisfaction is the main engine for all operations implemented in any business organization. In addition, communication among all the employees encourages on achieving cooperation and the planned aims highly and efficiently. So, organizations are interested in achieving the satisfaction of the employees in a way gains in growth, benefits, maintaining a good competitive position and achieving excellence in its performance. The Jordanian companies for investment and supply must pay attention to the elements and factors of organizational culture in which they coordinate all activities and procedures to execute all needs and requirements of the employees. Therefore, the problem of the study is to identify role playing by the organizational culture and its impact on job satisfaction in the Jordanian companies of investment and supplies.
\end{abstract}

\section{Keywords}

Impact of Organizational, Culture on Employee's, Satisfaction, Business Organization

\section{Introduction}

In light of the transformations and new changes which take the institutions, such as globalization, the freedom of these institutions must adapt to these changes in order to be allowed to succeed the key to its success and the best way to achieve their goals, for institutions to recognize its importance, the creation of the department of its own, in addition to the emergence of the topic of job satisfaction, which was of great importance by researchers in the areas of organizational be- 
havior. It stems the importance of job satisfaction for individuals from the special nature of the human component, which is composed of its members in the emotions and feelings of the work performed by the environment surrounding. It is a function of human happiness and stability.

The rapid development of information and communication technologies of the key elements that affect the administrative reorganization including the reflected on the level of performance and the regulatory environment plays a significant role in facilitating the use of technology. The environment includes all of the physical and human factors within the organization, where the environment is composed of rules and procedures and the quality of technical assistance and management laws, therefore, the work environment can help to facilitate and encourage the use of the high degree of technical assistance, or hindrance, it may also affect the methods and patterns used.

Job satisfaction is one of the most significant factors in the work environment. It is considered as an important indicator for measuring the effectiveness of the organization. Also, it is a term in which the employees feel that they are in charge of work and able to achieve the organization goals in all circumstances. It can be described as a work experience of an employee [1].

Defining job satisfaction is a difficult issue due to multiple and different orientations of the researchers towards it [2]. It is defined as a sentimental state related to the personal efforts or professional experience. It is based on special aspects such as nature of the work, employees, supervision, payment, promotions and the organizational communication channels [3] [4].

Defined the job satisfaction as an internal of what the employee achieves to satisfy his needs, desires, and expectations of the work environment.

[5]: "it is a positive or negative sentimental state that expresses the extent of achieving the work and the organizational objectives implemented by the employees.

[6]: defined job satisfaction as positive direction exerted by the employees toward their work. These statues might reflect the degree of interaction among the characteristics of the individual, the job, and the corporation. It is affected by different factors: demographic factors (age, intelligence, personal experience, and the professional capacity), personal factors (membership, friendly relations among all employees, participation in decision-making process), environmental factors (work content, professional growth, a chance of promotion, and the methodology of management and supervision). The studies indicate that the organizational commitment to its responsibilities towards the employee and the involvement of the employee in their decisions have a significant role in reflecting the satisfaction of the employee to the organization and to their organizational commitment. So, the employees would love their work, their organizations and they would do the required work enthusiastically [7] [8] [9].

Human resource is considered as one of the most important elements in the present time because the human is the main element who supports the abilities 
of the organization. So, the organizations and the companies as well strive to maintain, develop, and enhance the human resources. Moreover, they facilitate dealing with all employees and solving the problems between the employees and the management. This is reflected positively on raising their ethics and career stability [10]. The significance of job satisfaction is still in the organization priorities because of the procedure of developing work lifestyles. So, Job satisfaction may be classified into two fields: The internal public audience where public relations provide many of the needs of the public which consists of employees and the external audience which is in some segments of dealers and suppliers and the general segments of society in addition to various types of government or private institutions [11].

\section{Work Paper}

Clearly, many researchers around the world were interested in this topic; its factors, effect and impact on the individuals and the society as well [12], conducted a study which aimed at identifying the organizational factors and conditions affecting on Institute of Public Administration. The study reached the following results:

1) There was a statistically significant between the role of the employee and job satisfaction.

2) There was a statistically significant between job content and job satisfaction.

3) There was a relationship between leadership style and the degree of job satisfaction at the institute.

There are many factors effect on the job satisfaction of the employees such implemented promotions, the nature of the relations among the employees, circumstances of the work environment.

[13] conducted a study aimed at identifying the level of professional satisfaction for the female and male teachers of private schools. The study reached the following results: there were statistically significant for the impact of job satisfaction on the both gendered-teachers according to variables of gender and there were no signs on the scientific level.

In addition Conducted a field study aimed at developing a conceptual framework on the concepts of employee satisfaction and the impact on quality factors [14]. In addition to knowledge of some factors affecting the satisfaction of employees in achieving the quality of hotel services that have been provided, the sample included 30 guests reserved in Palestine Hotel. The results showed that there was a relationship between the degree of satisfaction and the weakness and quality of the services that have been provided. The reason is that the requirements that gave rise to a state of satisfaction were improved considering the performance [15]. Conducted an exploratory study aimed at verifying support and leadership confidence in building employee commitment. The result of the study showed the following results: leadership confidence and leadership sup- 
port were positively correlated with staff commitment [16]. Conducted a study aimed at identifying the implications of professional values and organizational support. The sample of the study consisted of 151 Chinese employee. The survey was used as a tool for study. The standard deviation was used to measure the effect of variables on job satisfaction. The results of the study showed that there are three criteria for professional values: self-realization, worker cleanliness, and social status. Also, those professional values that perceived organizational support have had an impact on success [17]. Conducted a study aimed at identifying the impact of organizational support on expatriates and their willingness to survive and their adaptation abroad. The study sample consists of 50 Taiwanese and 10 Vietnamese executives were interviewed for Taiwanese companies. The results of the study indicated that the expatriate who receives training focuses on technical skills rather than on cultural adaptation and that there is a positive impact of organizational support on adaptation [18]. Conducted a study aimed at understanding the relationship between adaptation to work, level of achievement and the impact of organizational support on employees of multinational companies. The study sample consists of 400 Korean employees at the US military bases in South Korea where staff Koreans and Americans work together, using the coefficient of constancy and correlation to measure variables. The study showed a relationship between the cultural intelligence of working individuals and the organizational support for the development and success of the profession in multinational organizations and cultures.

A study by Safari and his colleagues aimed at identifying the causes of turnover, the impact of the organizational justice and organizational support, which is aware of the scarcity of job opportunities. The study sample consists of 150 administrative staff from Isfahan University, Iran. The questionnaire tackled two main areas: Organizational justice, and functional justice [19]. One of the study results was having a negative impact on both organizational justice and organizational support on employment opportunities.

Conducted a study aimed at revealing the degree of job satisfaction and organizational commitment of the administrators of three official Jordanian universities to find out whether there were statistically significant differences in the degree of satisfaction and commitment due to gender, job, experience, qualifications, and salary. The results of the study indicated that the degree of job satisfaction was moderate, while the degree of organizational commitment was significant. The results showed that the degree of job satisfaction and organizational commitment from the employees' point of view is not different according to the variables of gender, scientific qualification, experience, and monthly salary as well. Aimed at revealing the relationship between job satisfaction and organizational commitment among faculty members in many al-Ghadharah schools in Andhra, the study was followed by a random sample of 100 faculty members ( 50 males and 50 females) from 15 different management colleges in 
the region. To achieve the objectives of the study, a questionnaire was implemented consists of (25) items distributed at the fields of: salary, promotions, relationship with colleagues, and supervision. After the data collection and analysis, the results of the study showed that the level of job satisfaction ranged from low in the dimensions of salary, promotions and average in the areas of relationship with colleagues and supervision. The results showed that there were no statistically significant differences in the level of job satisfaction due to the gender variable. Differences were found in the variables of academic qualification and academic rank. The study showed a significant correlation between the level of job satisfaction and the level of organizational commitment of the faculty member.

The Study that aims at uncovering the relationship between psychological combustion and job satisfaction among faculty members of dental faculties in Saudi Arabia, The study followed a survey methodology using a simple random sample consisting of 31 students and 17 faculty members who responded to an electronic questionnaire consisting of two parts. The first included the maslash scale of psychological combustion and the job satisfaction questionnaire of the dentist. The results of the study showed that the level of psychological combustion in the sample ranged between average and high, the students are higher, and that the level of job satisfaction at the side of faculty members was higher than that of students who came low, especially in the lack of time to study enough. The results showed an inverse correlation between job satisfaction and psychological burnout. The lower the job satisfaction, especially in the material fields, the workload, and labor relations, the greater the combustion among faculty members, the higher the pressure of study and the lower the student's leisure time, the higher the combustion and the less job satisfaction.

Based on the above literature review, the present study aims at identifying the role played by organizational culture and its impact on employee's satisfaction by applying the present study on the investment Jordanian companies at HKJ.

\subsection{The Main First Question}

What is the impact of organizational culture (commitment, management support, internal and external communication) on the employees' satisfaction in the Jordanian companies of investment and supplies?

1) What is the impact of organizational commitment on employee's satisfaction in the Jordanian companies for investment and supplies?

2) What is the impact of management support on employee's satisfaction in the Jordanian companies for investment and supplies?

\subsection{The second Main Question}

Is there any statistically significant at $(\alpha \geq 0.05)$ in evaluating the sample of the study according to the demographic level (Gender, experience years, qualification level, job description)? 


\subsection{Significant of the Study}

1) Clarifying the role of organizational culture factor and its impact on employees' satisfaction.

2) The results of the study help the decision makers to base strong strategies able to improve employees' satisfaction.

\subsection{Objectives of the Study}

The study aimed at identifying the level of using and applying organizational culture at Jordanian companies for investment and supplies. Also, it aims at identifying the impact of organizational commitment, external and internal communication on employees' satisfaction. The extent of employees' satisfaction can be based on demographic variables (gender, experience years, qualification, and professional level).

\section{Definitions of the Study}

Organization culture: It is defined as a set of values, beliefs, customs, behavior patterns, and individual behaviors of an organization.

\subsection{The Commitment of the Organization}

The fulfillment of the commitments and conditions between the organization, employees and the participation of decision-makers and the provision of a suitable environment and environment for work and health care are defined.

\subsection{Management Support}

It is defined as an indicator of FAO's willingness to increase rewards for work efforts and indicators of the extent to which the organization provides assistance when needed.

\subsection{Employee Satisfaction}

It is defined as the viewpoint of the employees of the organization towards their work, which stems from their understanding of personal, organizational and environmental aspects, which in turn generate satisfaction, whether positive or negative.

\subsection{Limitations of the Study}

- It is applied only to all employees of Jordanian companies for investment and supplies (Safeway Store, 2016).

- The results of the study can be known by the tools used and its validity and how much matching sample of the study.

\section{Methodology of the Study}

The descriptive approach has been utilized based on nature of the study. 


\subsection{Sample of the Study}

A Sample of the study consisted of all employees of Jordanian company for investment and supplies. (250) questioners have been distributed randomly. The retrieved was (210) forming (84\%). Herewith is a Table 1 describing a sample of the study according to demographic levels: gender, experience, qualification, and position.

Table 1 indicates that:

- Percentage of male (176) (83.8\%) representing the majority of the sample of the study. Whereas female (34) and the percentage was (16.2\%) from the sample of the study. As per the researcher, most of the employees were males. Although the researcher is keen on the female component to be an acceptable rate for the purposes of this study.

- The result of the sample showed category (less than 5 years' experience) (80) formed (38.1\%) from a sample of the study, (from 5 - 10 years' experience) (111) formed (52.9\%), the experience (from were 18. Those whose their experience (more than 15 years) were $(0.5 \%)$ formed by one employee.

- The results of the job title showed that the percentage of employees with a diploma reached to (48) employees forming (22.9\%), and who have degree of a bachelor were (162) employees forming (77.1\%). This may be due to the adoption of the diversity of the company's needs to the qualifications appropriate to the nature of its work.

Table 1. Sample of the study according to demographic level $\mathrm{N}=210$.

\begin{tabular}{|c|c|c|c|}
\hline Demographic variables & Categories & Frequency & Percentage \\
\hline \multirow{2}{*}{ Gender } & Male & 176 & $83.8 \%$ \\
\hline & Female & 34 & $16.2 \%$ \\
\hline \multirow{5}{*}{ Years of experience } & Less than 5 years & 80 & $38.1 \%$ \\
\hline & $5-10$ years & 111 & $52.9 \%$ \\
\hline & $10-15$ years & 18 & $8.5 \%$ \\
\hline & 15 - 20 years & 1 & $0.5 \%$ \\
\hline & More than 20 years & 0 & $0 \%$ \\
\hline \multirow{2}{*}{ Qualification } & Diploma & 48 & $22.9 \%$ \\
\hline & Bachelor & 162 & $77.1 \%$ \\
\hline \multirow{7}{*}{ Profession } & Management & 34 & $16.2 \%$ \\
\hline & Store & 15 & $7.1 \%$ \\
\hline & Marketing & 66 & $30 \%$ \\
\hline & Accounting & 41 & $19.5 \%$ \\
\hline & Control & 20 & $9.5 \%$ \\
\hline & IT & 14 & $6.7 \%$ \\
\hline & Human Resource & 23 & $11 \%$ \\
\hline
\end{tabular}


- The number of mangers was (34), (16.2\%), the number of employees was (15) and their percentage was (7.1\%). The percentage of accounting was (19.5\%), and they were (41) Information technology was (6.7\%), and human resources (11\%) with 23 employees.

\subsection{Stability Tool of the Study}

To verify the stability of the tool, the internal consistency coefficient (Cronbach Alpha) was calculated. The stability coefficient values for the main content of the questionnaire ranged between (0.8401) and (0.9468). These values are acceptable for the purposes of this study. Table 2 Stability coefficient:

\subsection{Identifying Levels of Responding}

The questionnaire of the study consisted of (30) paragraphs. Likert Five Point Scale was used to determine the level of answers in the study. (X) Was used for an answer that reflects their approval, whether very high-grade, highly agreeable, moderately agreeable, low-grade, or very low-grade, to estimate the level of response to the study axes from the perspective of employees of Safeway Jordan. Three levels of accounting averages have been adopted as follows:

- From 1 to 2.33 degrees of little approval.

- From 2.34 to 3.66 degrees average approval.

- From 3.67 to 5 degree high approval.

\subsection{Analytical and Methodology}

Method of a package for social sciences statistical (SPSS) was used for data analysis.

The following statistical analysis methods were used:

1) Frequencies and percentage to describe feature study sample.

2) Cronbach Alpha to verify the stability of the tool.

3) Standard deviations and means to answer the questions of the study.

4) ANOVA analysis to show statistical differences among variables that have more than two categories (gender, experience, qualification and job title).

\subsection{Variables of the Study}

1) Independent Variables:

a) Organization Commitment.

Table 2. Consistency coefficient Cronbach Alpha, $\mathrm{N}=210$.

\begin{tabular}{ccc}
\hline Cronbach Alpha & Paragraphs & Sections of the study \\
\hline 0.9468 & $5-11$ & Organization commits to achieving employ satisfaction \\
0.8401 & $12-16$ & Management support employee satisfaction \\
0.8404 & $17-22$ & $\begin{array}{c}\text { Impact of internal and external } \\
\text { communication on employees' satisfaction }\end{array}$ \\
0.8818 & $23-30$ & Employees satisfaction \\
\hline
\end{tabular}


b) Management Support.

c) Internal and External Communication.

2) Dependent Variable: Employees Satisfaction.

\section{Questions of the Study \& Discussion the Results}

The main first question:

What is the impact of organizational culture (commitment, management support, internal and external communication) on the employees' satisfaction in the Jordanian companies of investment and supplies?

What is the impact of organizational commitment on employee's satisfaction in the Jordanian companies for investment and supplies?

To answer the above-mentioned question, Means, standard deviations, frequencies, and percentages were extracted. Table 3 is showing:

This section of the study includes (7) paragraphs in which it is discussing organization satisfaction and its impact on employees' satisfaction in the Jordanian companies of investment and supplies. Table 3 shows onions community of the study in which it was moderate and reached (3.65). The standard deviation was (0.78 - 0.89) which means that deviation among the employees was large. Means and standard deviations were also extracted for every paragraph of the sample of the study as shown in Table 3.

Paragraph (4) was in first rank in which the arithmetic mean was (3.73) with high degree. Paragraph (3) was in the second rank in which arithmetic mean was (3.71) with high level. The researcher attributed this result to the importance of the commitment of the organization to involve the administrative matters and take their views to make the interest of the company not only to the managers but to everyone in the company.

Table 3. Arithmetic, standard deviations for sample of the study.

\begin{tabular}{|c|c|c|c|c|}
\hline No. & Paragraphs & Mean & Standard deviations & Degree \\
\hline 1 & $\begin{array}{l}\text { Employees of different divisions of the } \\
\text { Safeway participate in the work teams. }\end{array}$ & 3.48 & 0.89 & Moderate \\
\hline 2 & $\begin{array}{l}\text { Safeway provides employees with } \\
\text { a clear vision of the nature of the } \\
\text { work they perform. }\end{array}$ & 3.67 & 0.82 & High \\
\hline 3 & $\begin{array}{l}\text { Safeway works to involve staff from } \\
\text { various departments in the teams. }\end{array}$ & 3.71 & 0.78 & High \\
\hline 4 & $\begin{array}{l}\text { Safeway provides employees with full } \\
\text { knowledge of work-related policies. }\end{array}$ & 3.73 & 0.83 & High \\
\hline 5 & $\begin{array}{l}\text { Sefawy's functional divisions work } \\
\text { together to help each other. }\end{array}$ & 3.61 & 0.89 & Moderate \\
\hline 6 & $\begin{array}{l}\text { The cooperation between the various } \\
\text { functional divisions of Safeway is common. }\end{array}$ & 3.69 & 0.89 & High \\
\hline 7 & $\begin{array}{l}\text { Safeway is committed to uniting the } \\
\text { common objectives of the employees. }\end{array}$ & 3.67 & 0.87 & High \\
\hline \multicolumn{2}{|r|}{ Organization commits in employees' satisfaction } & 3.65 & 0.74 & Moderate \\
\hline
\end{tabular}


To answer the above-mentioned question. Means, standard deviations, frequencies, and percentages were extracted. Table 4 is showing:

This section of the study includes (5) paragraphs in which it is discussing organization commitment and its impact on employees' satisfaction in the Jordanian companies of investment and supplies. Table 4 shows opinions community of the study in which it was high and reached (4.10). The standard deviation was (0.73 - 0.61) which means that deviation among the employees was large. Means and standard deviations were also extracted for every paragraph of the sample of the study as shown in Table 4.

Paragraph (1) was in first rank in which the arithmetic mean was (4.15) with high degree. Paragraph (5) was in the second rank in which arithmetic mean was (4.13) with high level. The researcher attributed this result to the significance of improvement and orienting the employees because it is the main and vital factor in which contributes to developing the human resources in all tasks and missions. Absolutely, it is one of the most aims that the employees seek to achieve in the company to achieve their satisfaction.

What is the impact of external and internal communication in achieving the employees' satisfaction at the Jordanian companies of investment and supplies?

To answer the above-mentioned question. Means, standard deviations, frequencies, and percentages were extracted. Table 5 is showing:

This section of the study includes (6) paragraphs in which it is discussing organization commitment and its impact on employees' satisfaction in the Jordanian companies of investment and supplies. Table 5 shows opinions community of the study in which it was moderate and reached (3.00). The standard deviation was (1.24 - 1.43) which means that deviation among the employees was large. Means and standard deviations were also extracted for every paragraph of the sample of the study as shown in Table 5.

Paragraph (2) was in first rank in which the arithmetic mean was (3.39) with moderate degree. Paragraph (1) was in the second rank in which arithmetic

Table 4. Arithmetic, standard deviations for sample of the study.

\begin{tabular}{|c|c|c|c|c|}
\hline No. & Paragraphs & Mean & Standard deviations & degree \\
\hline 1 & $\begin{array}{l}\text { Safeway management seeks to } \\
\text { develop the skills of employees. }\end{array}$ & 4.15 & 0.67 & High \\
\hline 2 & $\begin{array}{l}\text { Safeway seeks to motivate } \\
\text { employees to achieve business objectives. }\end{array}$ & 4.08 & 0.61 & High \\
\hline 3 & $\begin{array}{l}\text { Safeway's management determines } \\
\text { a specific function for each worker. }\end{array}$ & 4.05 & 0.73 & High \\
\hline 4 & $\begin{array}{l}\text { Safeway management allows all } \\
\text { employees to know their development plans. }\end{array}$ & 4.08 & 0.61 & High \\
\hline \multirow[t]{2}{*}{5} & $\begin{array}{l}\text { Safeway seeks to transfer best practice } \\
\text { from one department to another. }\end{array}$ & 4.13 & 0.65 & High \\
\hline & $\begin{array}{l}\text { The extent of management } \\
\text { supports employee satisfaction }\end{array}$ & 4.10 & 0.51 & High \\
\hline
\end{tabular}


Table 5. Arithmetic, standard deviations for sample of the study.

\begin{tabular}{|c|c|c|c|c|}
\hline No. & Paragraph & Mean & $\begin{array}{l}\text { Standard } \\
\text { deviation }\end{array}$ & Degree \\
\hline 1 & $\begin{array}{l}\text { Communicating with senior } \\
\text { management at Safeway is easy. }\end{array}$ & 3.31 & 1.36 & Moderate \\
\hline 2 & $\begin{array}{l}\text { Safeway uses all channels of communication } \\
\text { between various bodies and departments. }\end{array}$ & 3.39 & 1.24 & Moderate \\
\hline 3 & Safeway uses the latest means of communication. & 2.30 & 1.36 & Low \\
\hline 4 & $\begin{array}{l}\text { Safeway's communications system provides the } \\
\text { necessary information about the external environment. }\end{array}$ & 3.00 & 1.37 & Low \\
\hline 5 & $\begin{array}{l}\text { Safeway uses all communication } \\
\text { channels in all directions. }\end{array}$ & 3.04 & 1.35 & Moderate \\
\hline \multirow[t]{2}{*}{6} & $\begin{array}{l}\text { Safeway works to facilitate communication between } \\
\text { technical departments and the external environment. }\end{array}$ & 2.78 & 1.34 & Moderate \\
\hline & $\begin{array}{l}\text { The impact of internal and external } \\
\text { communication on employee satisfaction }\end{array}$ & 3.00 & 1.01 & Moderate \\
\hline
\end{tabular}

mean was (3.31) with a moderate level. The researcher attributed this result that administrative communication has a significant role in increasing level of performance especially when the administrative instruction reached in the appropriate time. For sure, less of communication there is, less of cooperation among the employees will be. Therefore, paragraph (3) has taken the last level in which the arithmetic mean was (2.30) with low degree. From the perspective of the researcher, the company does not use means of modern communication in which the employee can observe it in many huge companies outside.

\section{The Second Main Question:}

Is there any statistically significant at ( $\alpha \geq 0.05)$ in evaluating the sample of the study according to the demographic level (Gender, experience years, qualification level, job description)?

To answer the question, Means, standard deviations, frequencies, and percentages were extracted due to demographic variables (gender, experience years qualification and job description). To clarify the statically significant among the arithmetic means, ANOVA has been used. Table 6 shows:

Paragraph (1) was in first rank in which the arithmetic mean was (3.97) with high degree. Paragraph (7) was in the second rank in which arithmetic mean was (3.90) with high level. The researcher attributed this result because of identifying needs of the employees form large importance in improving the performance of the employees and encouraging them to do whatever efficiently and perfectly. In Safeway, employees' satisfaction is considered a pillar which was highly appearing in this company. Table 7 shows the results of ANOVA to clarify the statistically significant among all individuals.

Table 7 shows that it is no statistically significant at $(\alpha \geq 0.05)$ due to demographic variables (gender, experience, qualification, and job description) regarding employees' satisfaction at Jordanian companies of investment and supplies. 
Table 6. Arithmetic, standard deviations for sample of the study.

\begin{tabular}{|c|c|c|c|c|}
\hline No. & Paragraphs & Mean & Standard deviation & Degree \\
\hline 1 & $\begin{array}{l}\text { Safeway seeks to provide the } \\
\text { needs of its employees. }\end{array}$ & 3.97 & 0.76 & High \\
\hline 2 & $\begin{array}{l}\text { Officials in Safeway listen to the workers' } \\
\text { opinions and appreciate their apology. } \\
\text { Get enough motivation from Safeway. }\end{array}$ & 3.67 & 0.94 & High \\
\hline 3 & $\begin{array}{l}\text { I am taking enough promotions } \\
\text { from Safeway. }\end{array}$ & 4.02 & 0.75 & High \\
\hline 4 & $\begin{array}{l}\text { My job at Safeway is a source } \\
\text { of strength for me. }\end{array}$ & 3.81 & 0.82 & High \\
\hline 5 & $\begin{array}{l}\text { I find the administrative } \\
\text { procedures at Safeway company clear. }\end{array}$ & 3.80 & 0.74 & High \\
\hline 6 & $\begin{array}{l}\text { Safeway provides employees } \\
\text { with many facilities. }\end{array}$ & 3.86 & 0.74 & High \\
\hline 7 & I am satisfied with my work in Safeway. & 3.90 & 0.62 & High \\
\hline 8 & I am proud to work in Safeway. & 3.86 & 0.68 & High \\
\hline & Extent of employees' satisfaction & 3.86 & 0.56 & High \\
\hline
\end{tabular}

Table 7. Results of ANOVA to clarify the statistically significant among all individuals regarding employees' satisfaction due to gender $(\mathrm{N}=210)$.

\begin{tabular}{cccc}
\hline Variable & Section & F Value & Statistically significant \\
\hline Gender & Employees satisfaction & 0.094 & 0.759 \\
Experience & Employees satisfaction & 0.174 & 0.677 \\
Qualification & Employees satisfaction & 3.263 & 0.072 \\
Job description & Employees satisfaction & 0.432 & 0.512 \\
\hline
\end{tabular}

Therefore, no statistical significance for any category in which all were equal. So, the result indicates acceptance of the hypothesis.

\section{Results of the Study}

The present study has reached for following results:

1) Safeway (the Jordanian company for investment and supplies) commit to involve the employees in the administrative decisions and let them participate in make company's interest to the shoulders of all employees and managers.

2) The degree of organization commitment representing in involving the employees in a different level of management was high.

3) Orientation and development are considered important for all employees because of the vital factor in which improving the human resource to do all tasks and missions in the Jordanian company for investment and supplies (Safeway).

4) The degree of management supports the employees was high in the Jordan Investment and Supply Company, which is to develop the skills of the employees and motivate them to achieve the objectives of the work and inform them of the development plans related to the organization. 
5) There is a moderate degree of the impact of internal and external communications on the satisfaction of employees.

6) Safeway uses all channels of communication among different employees and departments.

7) Communication with senior management at Safeway is considered easy.

8) Administrative communication is an important role and head in speed performance especially when administrative instructions arrive in a timely manner.

9) There is a high degree of satisfaction of employees at Jordan Investment \& Supply Company (Safeway).

\section{Conclusions and Recommendations}

Recommendations of the study have been provided for improving operations and work levels in our community efficiently and perfectly.

1) More studies should be conducted about organization culture and its impact on employees' satisfaction at all Jordanian institutions.

2) Commitment to applying organizational culture at all organizations in a way to have positive feedback can be effected by employees' satisfaction.

3) Conducting a deep study focuses on the obstacles which prevent applying organizational culture at the Jordanian and all Arab countries companies.

4) Senior management in any organization shall take into consideration the provision of incentives to employees, increase their salaries, involve them in administrative decisions and inform them of the plans of the Organization.

5) The relationship between management and employees shall be improved and enhanced because it has a significant role in improving the employee and the organization through appreciation and respect principles. Also, teamwork should be taken into consideration to increase employees' satisfaction.

6) Safeway and all Jordanian companies must use all means of modern communication in which the employees can observe it in global companies.

\section{References}

[1] Hammadi, A. (2016) Administrative Empowerment and Its Relation to Job Satisfaction: An Exploratory Study. Anbar University Journal of Economic and Administrative Sciences, 8, 105-173.

[2] Al-Rashidi, M. (2014) The Role of Public Relations in Enhancing the Functional Skills of University Employees: Kuwait University as a Model. Master Thesis, Middle East University, Amman.

[3] Taani, H. (2013) Job Satisfaction and Its Relation to the Organizational Commitment of Employees in the Official Jordanian University Libraries. Journal of Education Studies, 40, 181.

[4] Abbas, M. (2009) Employee Satisfaction and Its Impact on the Quality of Hotel Service. Journal of Management and Economics, 2, 215-256.

[5] Osama, A.M. (2012) Proposed Model for Career Development as an Input to Enhance Job Satisfaction and Commitment: A Field Study. New Horizons for Business Studies, 24, 47-75. 
[6] Murad, A. and Abdullah, S.A. (2014) The Impact of the Ethical Practice of HR Departments on Employee Satisfaction. Journal of Administrative Sciences Studies, 41, 388-401.

[7] Mohammed Bin Ali, A. (2014) Impact of the Relationship between Organizational Excellence and Quality of Career. Journal of Financial and Commercial Research, 1, 399-428.

[8] Akili, O. (2005) Strategic Human Resource Management: Strategic Dimension. Dar Wael Publishing and Distribution, Amman.

[9] Nada, Y. (2002) Attitudes of Academic Supervisors at Al-Quds Open University toward Open Education and Their Relationship to Their Job Satisfaction. Dissertation Unpublished Thesis, University of Neeline, Khartoum.

[10] Hazaime, A. (2009) Job Satisfaction for Faculty Members, Staff and Administrators in Private Universities. Journal of Humanities, 2, 2012-2056.

[11] Al-harthi, S. and Wahi, M. (2017) The Association between Burnout and Job Satisfaction among Dental Undergraduates and Faculty. JPDA Journal, 26, 45-53.

[12] Chung, Y. and Ho, C. (2012) The Organizational Support of Oversea Expatriates in Global Manufacturing Environment: The Case of Taiwanese Companies in Vietnam. International Journal of E-Education, Business, E-Management and ELearning, 2, 170-175. https://doi.org/10.7763/IJEEEE.2012.V2.103

[13] Diao, A. and Park, S. (2012) Culturally Intelligent for Satisfied Workers in a Multinational Organization: Role of Intercultural Communication Motivation. African Journal of Business Management, 6, 7296-7309.

[14] Madhuri, J. (2017) The Relationship between Job Satisfactions and Organizational Commitment among Faculty Members in Select Management Educational Institutions. The IUP Journal of Organizational Behavior, XVI, 33-53.

[15] Richard, G., Kim, M. and Koo (2017) Does Job Satisfaction Increase Sales and Customer Satisfaction? Evidence from Retail Banking in South Korea. B.E. Journal of Economic Analysis \& Policy, 17, 1-18.

[16] Safari, A., Tamizifa, M., Reza, J. and Ali, M. (2012) The Effect of Organizational Justice and Perceived Organizational Support on University Staff Job Success. $i B u-$ siness, 3, 274-282.

[17] Suma, S. and Lesh, J. (2013) Job Satisfaction and Organizational Commitment: The Case of Shkodra Municipality. European Scientific Journal, 9, 41-52.

[18] Yeh, C. and Hsieh, T. (2007) Study on the Management Styles and Job Satisfaction of Employees at Taiwan's Architectural Firms. The International Journal of Organizational Innovation, 10, 185-204.

[19] Yu, C. (2011) Chinese Knowledge Employee. Career Values, Perceived Organizational Support and Career. 